\title{
Silent Circulation of Rift Valley Fever in Humans, Botswana, 2013-2014
}

\author{
Claire E. Sanderson, Ferran Jori, Naazneen Moolla, \\ Janusz T. Paweska, Nesredin Oumer, Kathleen A. Alexander
}

We evaluated the prevalence of Rift Valley fever virus IgG and IgM in human serum samples ( $n=1,276)$ collected in 2013-2014 in northern Botswana. Our findings provide evidence of active circulation of this virus in humans in the absence of clinical disease in this region.

The World Health Organization considers Rift Valley fever (RVF) a priority disease because of its substantial public health impact and the lack of available interventions to prevent and halt epidemics (1). RVF virus (RVFV) is primarily transmitted to animals through infected Aedes and Culex mosquitoes, while human transmission has been attributed to direct contact with the blood and tissues of RVFV-infected livestock. RVF outbreaks have been challenging to forecast, with interepidemic or interepizootic years irregularly interspersed with epizootic years (2).

In Botswana, RVFV exposure and infection dynamics are incompletely understood. Despite numerous large-scale RVF outbreaks across southern Africa being reported to the World Animal Health Information Database (https://www.oie.int/wahis_2/public/wahid.php/Wahidhome/Home), no outbreaks in people have been detected in Botswana. However, previous surveys have found serologic evidence of virus exposure in humans (1959, 1984-1986), African buffalo (Syncerus caffer), and domestic cattle (3-5). According to the World

\footnotetext{
Author affiliations: Virginia Tech, Blacksburg, Virginia, USA, and Chobe Research Institute, Center for African Resources: Communities, Animals, and Land Use, Kasane, Botswana (C.E. Sanderson, K.A. Alexander); Animals, Health, Territories, Risks, Ecosystems Unit, Université de Montpellier, Montpellier, France, and Botswana College of Agriculture, Gaborone, Botswana (F. Jori); National Institute of Communicable Diseases, SandringhamJohannesburg, South Africa (N. Moolla, J.T. Paweska); University of the Witswatersrand, Johannesburg (J.T. Paweska); Botswana Ministry of Health, Gaborone (N. Oumer).
}

DOI: https://doi.org/10.3201/eid2610.191837
Animal Health Information Database, RFV disease outbreaks in Botswana have only been reported in livestock ( $\mathrm{n}=4$ outbreaks). It is presently unclear why low-level virus circulation has not been associated with detectable outbreaks in humans or how the virus is maintained during interepizootic years. Here, we evaluate archived human serum samples for evidence of RVFV-specific IgG and IgM and discuss the implications for public health in this region.

\section{The Study}

We determined the historical occurrence of suspected and documented cases of RVF in the human population in Botswana by evaluating inpatient records from Kasane Primary Hospital (Chobe District, 1962-2019) and nationwide monthly outpatient data from all 17 districts (1985-2019). Human serum samples $(n=1,276$; mean age 32 [SD \pm 12 ], range 1-91; 2013-2014) were collected from government health facilities within the Chobe District and screened using a recombinant nucleocapsid IgG indirect ELISA (6), with positive samples confirmed by inhibition ELISA (7). We screened IgG-positive samples for IgM using IgM-capture ELISA (8). This research was conducted with permission from the Botswana Ministry of Health and the Virginia Tech Institutional Review Board (Permit \#11-573).

We found no reports of RVFV infections, confirmed or suspected, from Botswana's passive health surveillance systems. Despite this, 5\% (95\% CI $4 \%-6 \%$ ) of serum samples tested positive for IgG (mean age 46 [SD \pm 17$]$, range 17-91; Table 1); of these, $11 \%(95 \%$ CI $5 \%-21 \%)$ were positive for IgM (mean age 32 years [SD \pm 8 ] range $24-47$ ). Both IgG- and IgM-seropositive samples were found across sampled years, but no significant differences could be detected by year of testing (IgG and IgM $\chi^{2}=0.27 ; p=0.60$ ) or season (seasonal data for IgG only available for 2013; $\chi^{2}=0.98 ; p=0.32$ ). However, all IgM-positive samples $(n=7)$ were obtained during the wet season (November 2013-February 
Table 1. Prevalence of Rift Valley fever virus IgG-positive human serum samples by sex and age group, Botswana*

\begin{tabular}{|c|c|c|c|c|c|c|c|}
\hline \multirow[b]{2}{*}{ Age group } & \multirow[b]{2}{*}{ Age, $y$} & \multicolumn{2}{|r|}{ Women } & \multicolumn{2}{|r|}{ Men } & \multicolumn{2}{|c|}{ Unknown } \\
\hline & & $\begin{array}{c}\text { No. } \\
\text { patients }\end{array}$ & $\begin{array}{c}\text { No. IgG positive } \\
(\%, 95 \% \mathrm{Cl})\end{array}$ & $\begin{array}{c}\text { No. } \\
\text { patients }\end{array}$ & $\begin{array}{c}\text { No. IgG positive } \\
(\%, 95 \% \mathrm{Cl})\end{array}$ & $\begin{array}{c}\text { No. } \\
\text { patients }\end{array}$ & $\begin{array}{c}\text { No. IgG positive } \\
(\%, 95 \% \mathrm{Cl})\end{array}$ \\
\hline Child & $<12$ & 15 & $0(0,0-20)$ & 17 & $0(0,0-18)$ & 2 & $0(0,0-66)$ \\
\hline Adolescent & $13-19$ & 57 & $1(2,0-9)$ & 9 & $0(0,0-30)$ & 1 & $0(0,0-79)$ \\
\hline Young adult & $20-24$ & 152 & $2(1,0-5)$ & 26 & $1(4,1-19)$ & 2 & $0(0,0-66)$ \\
\hline Adult & $25-44$ & 538 & $24(4,3-7)$ & 150 & $7(5,2-9)$ & 25 & $0(0,0-13)$ \\
\hline Middle-aged & $45-64$ & 78 & $7(9,4-17)$ & 45 & $4(9,4-21)$ & 4 & $1(25,5-70)$ \\
\hline Aged & $65-79$ & 5 & $1(20,4-62)$ & 10 & $5(50,24-76)$ & 1 & $0(0,0-79)$ \\
\hline Elderly & $>80$ & 5 & $2(40,12-77)$ & 3 & $2(67,21-94)$ & 0 & NA \\
\hline Unknown & NA & 11 & $1(9,2-38)$ & 6 & $2(33,10-70)$ & 114 & $5(4,2-10)$ \\
\hline Total & & 861 & $38(4,3-6)$ & 266 & $21(9,6-14)$ & 149 & $6(4,2-9)$ \\
\hline
\end{tabular}

2014). During the ensuing dry season, a RVF outbreak in livestock ( $n=2$ cows; July 2014) was reported in the Chobe Enclave (World Animal Health Information Database). In northern Botswana, rainfall and flood height affect mosquito dynamics, with models showing Culex pipiens mosquitoes to be most abundant in December (9), corresponding to human RVFV serological data previously collected in the region (5). The detection of IgM-positive patients confirms that RVFV was actively circulating in humans in the Chobe District in 2013 and 2014, with a single outbreak potentially associated with RVFV infection in both humans and livestock.

In South Africa, large RVFV outbreaks in livestock have occurred every 20-30 years, and concomitant infection in humans have occurred during these periods (10). In Botswana, no human infections have been recorded, nor have large outbreaks in livestock occurred, suggesting that the dynamics of RVFV transmission and persistence differ between these countries. This difference may be reflective of differing agricultural production intensities and livestock composition; the Chobe District solely supports subsistence farming and has fewer small domestic ruminants.

Overall, findings significantly differed by sex; men $(\mathrm{n}=266,9 \%, 95 \%$ CI $6 \%-13 \%)$ had higher IgG seroprevalence than women $(\mathrm{n}=861,4 \%, 95 \% \mathrm{CI}$ $3 \%-6 \%)\left(x^{2}=4.96, p=0.03\right.$; sex unknown, $n=149$; Table 1). In contrast, all IgM-positive patients were female, except for 1, for whom sex was unknown. Sex-specific roles in animal care and food preparation might influence RVFV exposure patterns. In the Chobe District, 54\% (95\% CI 46\%-61\%) of interviewed households owned livestock (11), and men predominately cared for $(97 \%, 95 \%$ CI $91 \%-99 \%$; K.A. Alexander, unpub. data) and slaughtered large livestock (12). It is unclear why IgM was detected only in women; however, women are involved in handling butchered meat in food preparation (12), and exposure differences may influence transmission risk from potentially infected animal tissues and fluids. Women $(46 \%, 95 \%$ CI $32 \%-61 \%)$ and men $(54 \%, 95 \%$ CI 39\%-68\%) both care for small livestock (K.A. Alexander, unpub. data).

When we sorted patients into 7 age groups, elderly ( $\geq 80$ years old) and aged (65-79 years old) patients had significantly higher seroprevalence levels than other age groups (Table 2). A significant difference was also detected between middle-aged patients (45-64 years old) and young adults (20-24 years old) (Table 2), possibly because older patients have been exposed more often to RVF outbreaks as a function of time. However, low sample sizes in the elderly and aged groups may have skewed our results. All IgM-positive patients were $24-47$ years of age. We found no evidence of RVFV in patients $<17$ years old, likely because of a lack of exposure to diseased animals (Figure).

Among seropositive patients, visits to health facilities were primarily for routine health care, HIV treatment and noninfectious disease. This finding suggests that RVF can occur with only mild or subclinical manifestations in affected people, which concurs with reports from other RVF- e $\mathrm{n} d$ e $\mathrm{m}$ i c regions (13). However, some IgG-positive patients

\begin{tabular}{|c|c|c|c|c|c|c|c|}
\hline Age group & Age, y & $\%, 95 \% \mathrm{Cl}$ & Adolescent & Young adult & Adult & Middle-aged & Aged \\
\hline Adolescent & $13-19$ & $2(0-8)$ & NA & NA & NA & NA & NA \\
\hline Young adult & $20-24$ & $2(0-5)$ & 1.00 & NA & NA & NA & NA \\
\hline Adult & $25-44$ & $5(3-6)$ & 0.404 & 0.158 & NA & NA & NA \\
\hline Middle-aged & $45-64$ & $9(5-15)$ & 0.0814 & 0.008 & 0.07 & NA & NA \\
\hline Aged & $65-79$ & $40(20-64)$ & $<0.001$ & $<0.001$ & $<0.001$ & 0.007 & NA \\
\hline Elderly & $>80$ & $50(22-78)$ & $<0.001$ & $<0.001$ & $<0.001$ & 0.01 & 0.7 \\
\hline
\end{tabular}

${ }^{*}$ Bold indicates significance ( $p$ value $<0.05$ by $x^{2}$ test). NA, not applicable. 


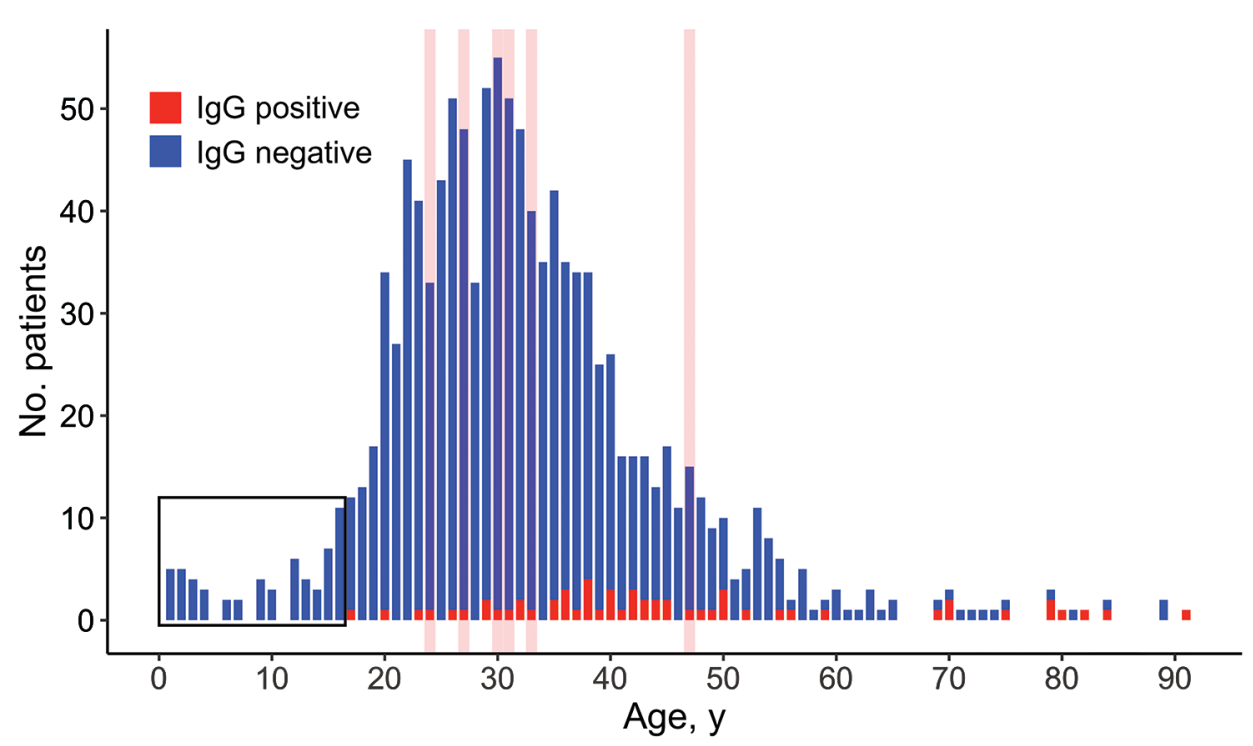

Figure. Number of Rift Valley fever virus IgG-positive and IgG-negative human serum samples by age at time of sampling, Botswana. The overlaid pink lines indicate the age of patients who also tested positive for Rift Valley fever virus IgM. No patients $<17$ years of age tested IgG positive for Rift Valley fever virus (black box). The figure was created in the open source statistical program $R$ version 3.6.1 (https://www. rproject.org) using ggplot2 (https://ggplot2.tidyverse.org).

in our study did have symptoms possibly attributable to RVF infection, including leg paralysis, swollen legs, and arthritis. Pregnancy was reported in 3 IgM-positive patients (43\%, 95\% CI 16\%-75\%); the outcomes of these pregnancies are unknown, but previous studies indicate that women infected with RVFV are 7 times more likely to miscarry than uninfected women (14).

Where data were available, we found a significant association between IgG seroprevalence and HIV status $\left(\chi^{2}=6.4 ; \mathrm{p}=0.01\right) ; 48 \%(95 \%$ CI $36 \%-61 \%)$ of IgG-positive patients were also HIV positive. It is unknown when these patients became infected with RVFV or HIV, but concurrent infection can increase the development of RVF symptoms involving the central nervous system, as well as fatality rates (15). Although nearly one third of IgM-positive patients were infected with HIV $(29 \%, 95 \%$ CI $8 \%-64 \%)$, we could not detect a significant association with HIV status $\left(\chi^{2}=0.67 ; p=0.4\right)$, likely because of the small sample size.

\section{Conclusions}

RVFV appears to be endemically circulating in northern Botswana, with people likely exposed to the virus regularly over time. Whereas viral reservoirs are uncertain, both livestock and wildlife present potential opportunities for human exposure to RVFV. In Botswana, government hospitals use syndromic diagnoses to treat patients; however, because no human cases have been reported and the disease can be asymptomatic, many RVF cases are likely misdiagnosed or undiagnosed. Increased diagnostic capacity and public health awareness of RVFV in
Botswana is required to further elucidate risk factors associated with human infection, especially in highrisk populations. These findings underscore the urgent need for more intensive investigations into RVFV transmission and persistence at the humananimal-vector interface.

\section{Acknowledgments}

We thank the Botswana Ministry of Health and the Chobe District Health Team for their support on this project.

This project was funded by the National Science Foundation Dynamics of Coupled Natural and Human Systems (\#1518486) and Ecology and Evolution of Infectious Diseases (\#1518663).

\section{About the Author}

Claire E. Sanderson is a research associate in the Fish and Wildlife Conservation Department at Virginia Tech and the Research Coordinator at the Center for African Resources: Communities, Animals, and Land Use (CARACAL). Her research interests broadly encompass disease ecology, behavioral ecology, conservation biology, and population genetics.

\section{References}

1. Mehand MS, Al-Shorbaji F, Millett P, Murgue B. The WHO R\&D Blueprint: 2018 review of emerging infectious diseases requiring urgent research and development efforts. Antiviral Res. 2018;159:63-7. PubMed https://doi.org/10.1016/ j.antiviral.2018.09.009

2. Olive M-M, Goodman SM, Reynes J-M. The role of wild mammals in the maintenance of Rift Valley fever virus. J Wildl Dis. 2012;48:241-66. https://doi.org/10.7589/ 0090-3558-48.2.241 
3. Jori F, Alexander KA, Mokopasetso M, Munstermann S, Moagabo K, Paweska JT. Serological evidence of Rift Valley fever virus circulation in domestic cattle and African buffalo in northern Botswana (2010-2011). Front Vet Sci. 2015;2:63. https://doi.org/10.3389/fvets.2015.00063

4. Kokernot RH, Szlamp EL, Levitt J, McIntosh BM. Survey for antibodies against arthropod-borne viruses in the sera of indigenous residents of the Caprivi Strip and Bechuanaland Protectorate. Trans R Soc Trop Med Hyg. 1965;59:553-62. https://doi.org/10.1016/0035-9203(65)90158-6

5. Tessier SF, Rollin PE, Sureau P. Viral haemorrhagic fever survey in Chobe (Botswana). Trans R Soc Trop Med Hyg. 1987;81:699-700. https://doi.org/10.1016/ 0035-9203(87)90462-7

6. Jansen van Vuren P, Potgieter AC, Paweska JT, van Dijk AA. Preparation and evaluation of a recombinant Rift Valley fever virus $\mathrm{N}$ protein for the detection of IgG and IgM antibodies in humans and animals by indirect ELISA. J Virol Methods. 2007;140:106-14. https:// doi.org/10.1016/ j.jviromet.2006.11.005

7. Paweska JT, Mortimer E, Leman PA, Swanepoel R. An inhibition enzyme-linked immunosorbent assay for the detection of antibody to Rift Valley fever virus in humans, domestic and wild ruminants. J Virol Methods. 2005;127:108. https:/ / doi.org/10.1016/j.jviromet.2005.02.008

8. Paweska JT, Burt FJ, Swanepoel R. Validation of IgG-sandwich and IgM-capture ELISA for the detection of antibody to Rift Valley fever virus in humans. J Virol Methods. 2005;124:17381. https://doi.org/10.1016/j.jviromet.2004.11.020

9. Pachka H, Annelise T, Alan K, Power T, Patrick K, Véronique $\mathrm{C}$, et al. Rift Valley fever vector diversity and impact of meteorological and environmental factors on Culex pipiens dynamics in the Okavango Delta, Botswana. Parasit Vectors. 2016;9:434. https:/ / doi.org/10.1186/s13071-016-1712-1

10. Ngoshe YB, Avenant A, Rostal MK, Karesh WB, Paweska JT, Bagge $W$, et al. Patterns of Rift Valley fever virus seropositivity in domestic ruminants in central South Africa four years after a large outbreak. Sci Rep. 2020;10:5489. https://doi.org/10.1038/s41598-020-62453-6

11. Alexander K, Ramotadima M, Sanderson CE. The power of consensus: developing a community voice in land use planning and tourism development in biodiversity hotspots. Ecosyst Serv. 2018;30:350-61. https://doi.org/10.1016/ j.ecoser.2018.02.008

12. Mooketsi C. Butchery styles and the processing of cattle carcasses in Botswana. PULA: Botswana Journal of African Studies. 2001;15:108-24

13. Al-Hazmi M, Ayoola EA, Abdurahman M, Banzal S, Ashraf J, El-Bushra A, et al. Epidemic Rift Valley fever in Saudi Arabia: a clinical study of severe illness in humans. Clin Infect Dis. 2003;36:245-52. https://doi.org/10.1371/ journal.pntd.0002065

14. Baudin M, Jumaa AM, Jomma HJE, Karsany MS, Bucht G, Näslund J, et al. Association of Rift Valley fever virus infection with miscarriage in Sudanese women: a crosssectional study. Lancet Glob Health. 2016;4:e864-71. https:/ /doi.org/ 10.1016/S2214-109X(16)30176-0

15. Mohamed M, Mosha F, Mghamba J, Zaki SR, Shieh W-J, Paweska J, et al. Epidemiologic and clinical aspects of a Rift Valley fever outbreak in humans in Tanzania, 2007. Am J Trop Med Hyg. 2010;83(2_Suppl):22-7. https:/ / doi.org/ 10.4269/ajtmh.2010.09-0318

Address for correspondence: Kathleen Alexander, Virginia Tech, Integrated Life Sciences Building, 1981 Kraft Dr, Blacksburg, VA 24060, USA; email: kathyalx@vt.edu

\section{EID Podcast:}

\section{The Mother of All Pandemics}

Dr. David Morens, of the National Institute of Allergy and Infectious Diseases, discusses the 1918 influenza pandemic.

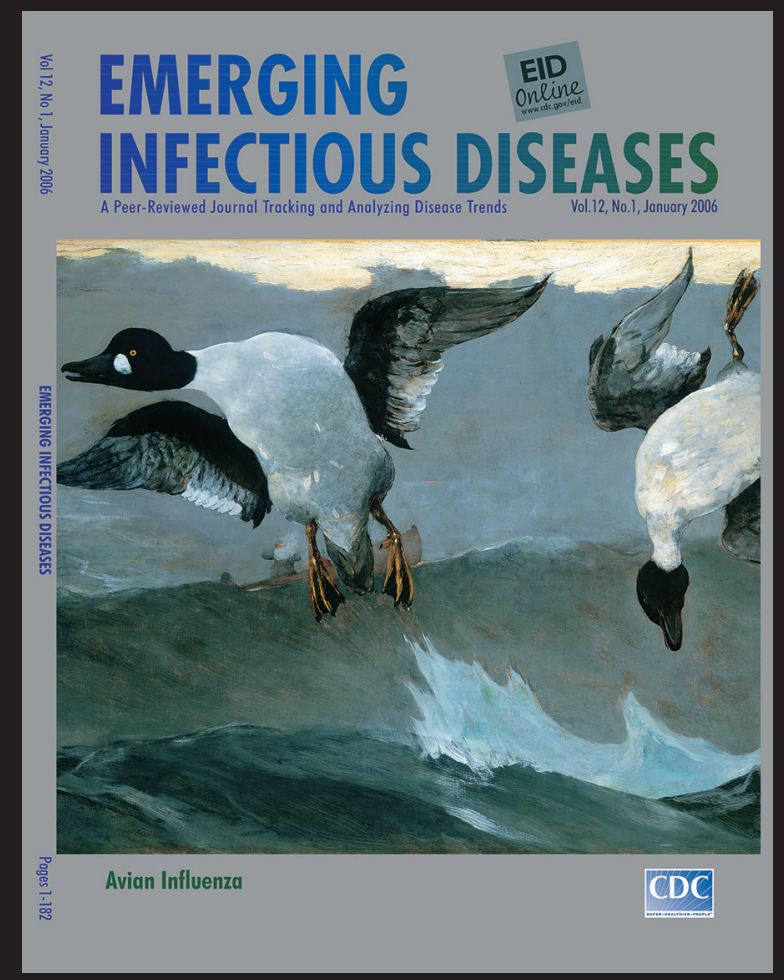

Visit our website to listen: https://tools.cdc.gov/medialibrary/ index.aspx\#/media/id/393805

EMERCING INFECTIOUS DISEASES" 